\title{
Investigation of the Milkfish (Chanos Chanos sp) Freshness by Infra-Red Spectroscopy
}

\author{
*Yus Rama Denny \\ Department of Physics Education \\ University of Sultan Ageng Tirtayasa \\ Indonesia Center of Execelenc for Food \\ Security (I-CEFORY), UNTIRTA \\ (Local Food Innovation) \\ Banten, Indonesia \\ *yusramadenny@untirta.ac.id \\ Untung Yudho Prakoso \\ Department of Electrical Engineering \\ University of Sultan Ageng Tirtayasa \\ Banten, Indonesia \\ untungyudhoprakoso@gmail.com
}

\author{
Endi Permata \\ Department of Electrical Engineering \\ Education \\ University of Sultan Ageng Tirtayasa \\ Banten, Indonesia \\ endipermata@untirta.ac.id \\ Kartina AM \\ Department of Agrotechnology \\ University of Sultan Ageng Tirtayasa \\ Banten, Indonesia \\ kartina_plg@yahoo.com
}

\author{
Teguh Firmansyah \\ Department of Electrical Engineering \\ University of Sultan Ageng Tirtayasa \\ Banten, Indonesia \\ teguhfirmansyah@untirta.ac.id
}

\begin{abstract}
The milkfish (Chanos Chanos sp) is one of the flagship products of Banten Province, Indonesia. As the export potential product, the freshness is needed to control its quality. In this study, we investigated the freshness of the fish by combining infra-red spectroscopy. The milkfish was taken directly from the fishpond was used as the experimental samples and varied in different condition: (1) complete fish body; (2) head and gills removed; (3) and fresh fillet. The samples were measured for 48 hours that recorded every 2 hours. It was seen that the spectroscopy can give us information about postmortem products such as pre-rigor and rigor mortis phases. The first and second samples showed that the freshness was decreased exponentially as a function of time under 14 hours of death in the rigor mortis phase. In contrary, the last one which prepared in fillet decreased linearly. The fishes that prepared with fillet have a high durability compared to the others. Our results demonstrated that the combined system of infra-red spectroscopy can conveniently and nondestructively evaluate the freshness of milkfish.
\end{abstract}

Keywords- milkfish, fish freshness, infra-red spectroscopy, non-destructive

\section{INTRODUCTION}

Milkfish is one of the many fisheries commodities produced in Banten. Milkfish is also one of the potential export products of Banten. As one of the potential products, high quality is a must such as high nutritional value, high protein, rich mineral content, good taste, and rich vitamins [1]. The stale fish meat is lack of nutrition value and not only the tasted bad, but also easy to cause poising. Therefore, the freshness of the fish is an important indicator for the quality of fish products. Freshness can be explained to some extent by some objective sensory, biochemical, microbial and physical parameters [2] that can cause damage to fish.

The freshness of fish traditionally is checked usually by looking at the appearance of fish and smell the fish. This method requires considerable experience and training. In addition, it sometimes produces different results from one person to another. The detection of the fish freshness has a significant guiding for processing, storage, and marketing of fish and fish product [3].

Numerous studies have attempted to explained for detection of fish freshness include sensory evaluation method, microbiological method, physical and chemical method, electronic noise technology, bio-impedance technology, image processing method, near infra-red spectroscopy [4]-[9].

In this research, we design a detector as an alternative tool that can detect fish freshness. This tool utilizes infrared spectroscopy to detect the level of freshness of fish. The infrared sensors used are arranged vertically with a combination of receivers in the middle of 2 transmitters. The method used is non-destructive. It does not directly touch the fish and is practical in its application. With this technology, it is expected to be an alternative for the fishing industry and the community to determine the level of freshness of fish effectively, efficiently and sustainably.

\section{METHOD AND EXPERIMENT}

The milkfish was taken directly from the fishpond was used as the experimental samples and varied in different condition: (1) complete fish body; (2) head and gills removed; (3) and fresh fillet. The samples were measured for 48 hours that recorded every 2 hours.

The stages of designing the fish freshness detector is shown in Figure 1. This tool starts from the design of the instrument followed by electronic and software design. Testing is done twice, the first test to determine the suitability of the measurement results with the program made. After the first test, the second test was successfully carried out by adjusting all electronic devices to the design of the casing.

This study produced a fish freshness detector that functions to measure fish freshness in real time with a digital display (LCD). Testing is done to see how far the level of response and function of the tool in measuring the freshness 
of fish. The method used is non-destructive, does not directly touch the fish and is practical in its application.

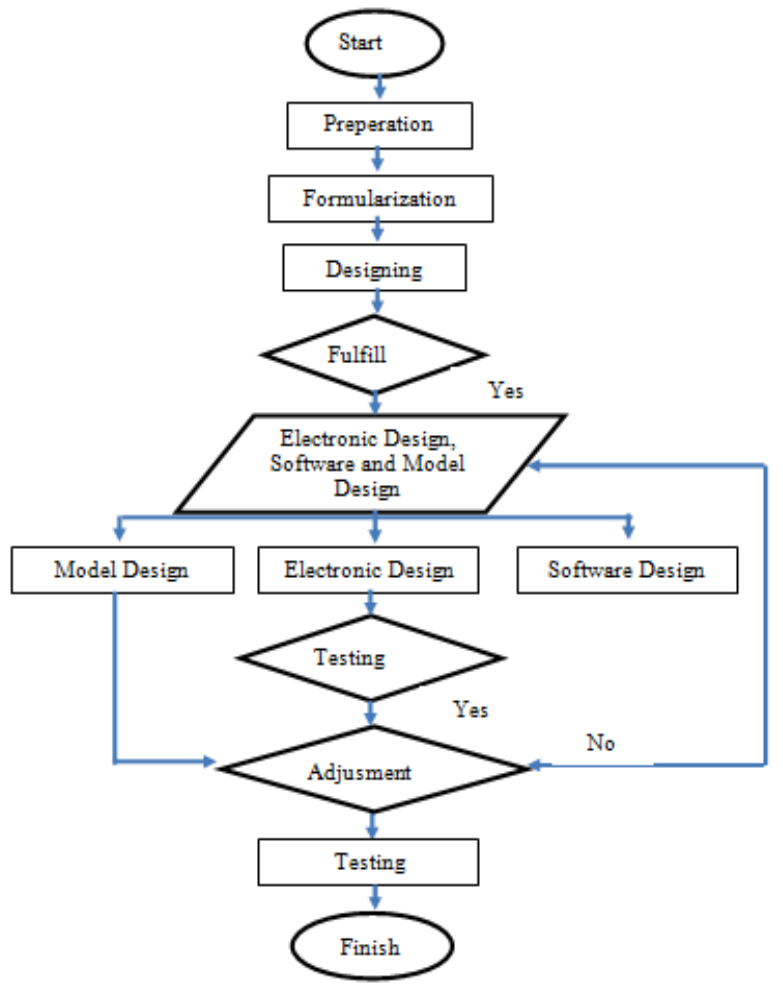

Fig. 1. Stages of designing prototype detection of milkfish freshness level

The basic principle of the fish freshness is shown in Fig. 2 and it can be described as follows: The infrared rays transmitted by infrared sensors will penetrate the layer of fish meat and inverted by fish meat. This backscattering energy will be received by the photodiode as a receiver. Changes in the backscatter that are received when the fish meat is measured, the value of this backscatter continues to be measured along with changes in the texture of fish meat [10].

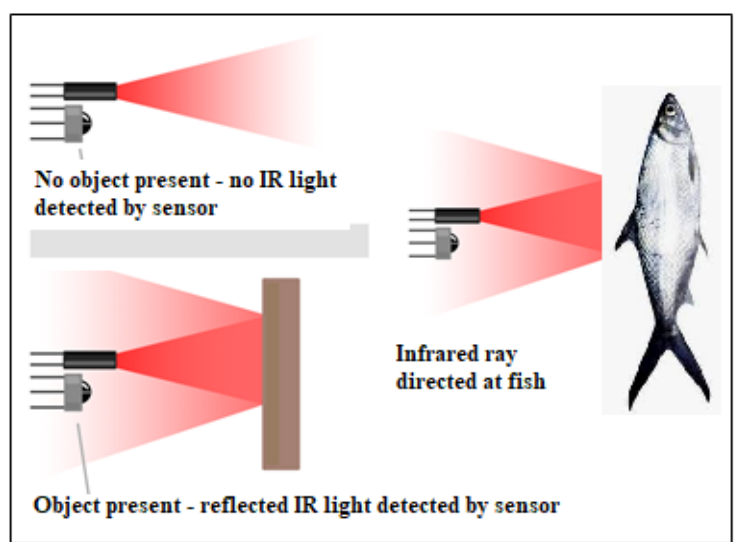

Fig. 2. Detection of freshness of milkfish based on infrared sensors [10].

The fish freshness detector is designed as shown in Fig. 3. The manufacture of tools starts from the design of the instrument followed by electronic design and software design. The first test is to determine the suitability of the measurement results with the program made. And then, continued with the adjustment of all electronic devices to the design of the instrument casing continued with a retest of the performance of the tools made.

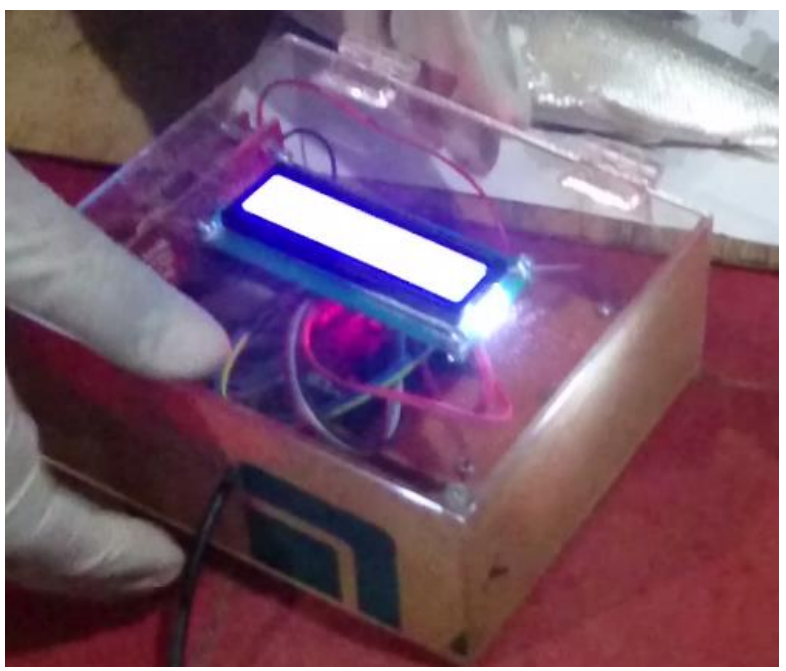

Fig. 3. The design of Fish Freshness Detector

The freshness detector of fish is divided into three system designs namely, electronic systems, software systems and design systems.

\section{A. Electronic Systems}

This fish freshness measurement tool is designed based on a scanning system. The infrared sensor used will be arranged vertically in combination with the receiver in the middle of 2 transmitters. In the sensor circuit where the sensor has a voltage source of 5 volts from the battery. This circuit is connected to the voltage reduction and voltage amplifier circuit in order to obtain a larger output range. This tool has a control section as a regulator of the system that is in it. The microcontroller as the center of the tool setting is ATMega 32 type which has four ports as output. This system circuit can be seen in Fig. 4.

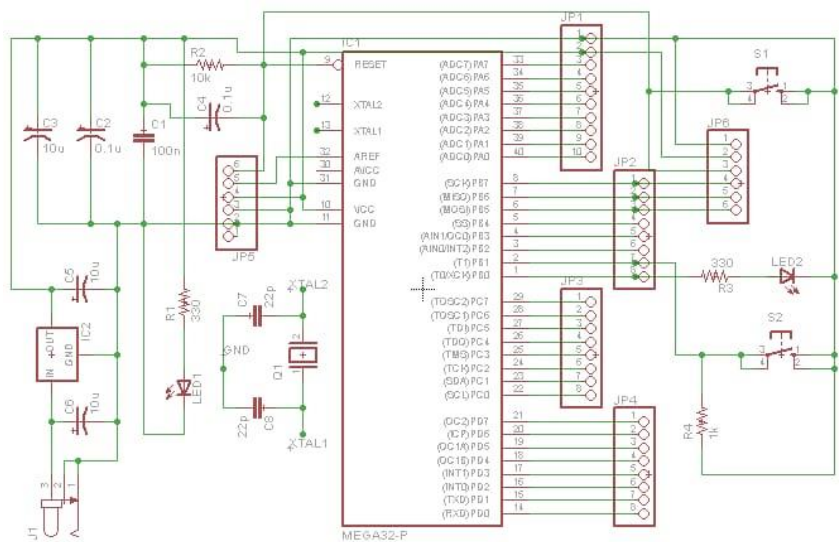

Fig. 4. Microcontroller Circuits

\section{B. Software Systems}

The software contained in the microcontroller is called a firm wire. This software system is made using CodeVision AVR software with the programming language used is $\mathrm{C}$ language. Firmware that has been created is downloaded to a microcontroller with Atmel AVRProg (AVR910). 


\section{Casing System}

This section is a place for electronic devices related to processing data from sensors and power supplies that are used like batteries. The tool has two parts, namely the body and the grip. On the body there is an LCD that displays the measurement results. Inside there is a battery storage area and socket SD card to record the data obtained.

\section{RESULTS AND DisCUSSIONS}

The milkfish was taken directly from the fishpond was used as the experimental samples and varied in different condition: (1) complete fish body (whole milkfish); (2) head and gills removed; (3) and fresh fillet. Those variables can be explained as follows:

\section{A. Reflection Pattern on Whole Milkfish}

Whole milk fish which is measured directly without any special treatment before, experiences a decreasing yield. The decrease in reflection occurs along with a decrease in the rate of quality with a smaller reflection value. The pattern of degradation of milkfish quality in the first 2 hours after death which is a pre-rigor period for milkfish [11], during that time there was a decrease in the intensity of infrared reflection. However, the decrease in the intensity of the reflection is not too significant, this is because the condition of the fish is still fresh.

The period after 12 hours of death, where the milk fish has entered the post rigor stage [11], followed by a significant decrease in the intensity of reflection. This is also accompanied by the condition of fish that have released fluids or mucus in their bodies, especially in the belly of the fish. At this time, aerobic breathing stops and anaerobic oxidation causes accumulation of lactic acid which causes a decrease in $\mathrm{pH}$ and loss of adenosine triphosphate (ATP) due to autolysis decomposition, causing muscle to become stiff as a result of unidirectional association (irreversible association) of myosin and actin molecules so that mucus quickly exits [11].

From the data obtained, it showed the intensity of the whole quality of milkfish degradation by using an infrared sensor, as follows:

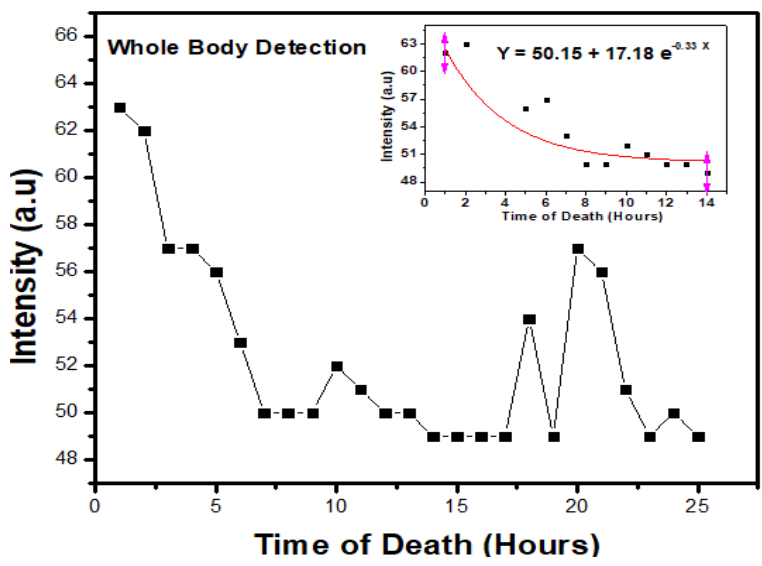

Fig. 5. Whole body detection of Milkfish

Figure 5 shows that after passing through the 12-hour period of death to the end of the measurement, the intensity of the infrared reflection is smaller than the 12-hour period of the initial. However, there is still a decrease in the intensity of reflection accompanied by the smell of foul odor and mucus that comes out of the fish more. This is because mucus contains nitrogen compounds which are very large and these compounds provide food for fish polluting microorganisms originating from the surrounding environment. In general, the quality of milkfish testing in 1 to 14 hours of death during the Rigormortis phase can be seen clearly. From Figure 5, the data of milkfish freshness level reflects the exponential decrease during the Rigormortis phase. The data has been fitted with the exponential equation as shown in the inset of Figure 5. It shows that the number of Fish Freshness Reduction Constant is about -0.33 and latter it will be compared with others measurements. In addition, the bacterial decomposition of the milk fish clearly seen in the time of deaths more than 17 hours.

\section{B. Reflection Pattern on Milkfish Skin On (whole fish without head and stomach contents)}

The intensity of infrared reflection on the Skin On detection of milkfish during the overall measurement was decreased. This is in line with the rate of decline in fish quality. The initial period of up to 2 hours after death there is a decrease in infrared intensity, but the intensity of the decrease is still small.

From the data obtained, a graph is made that shows the intensity of the decline in the quality of the milkfish condition on skin by using an infrared sensor, as follows:

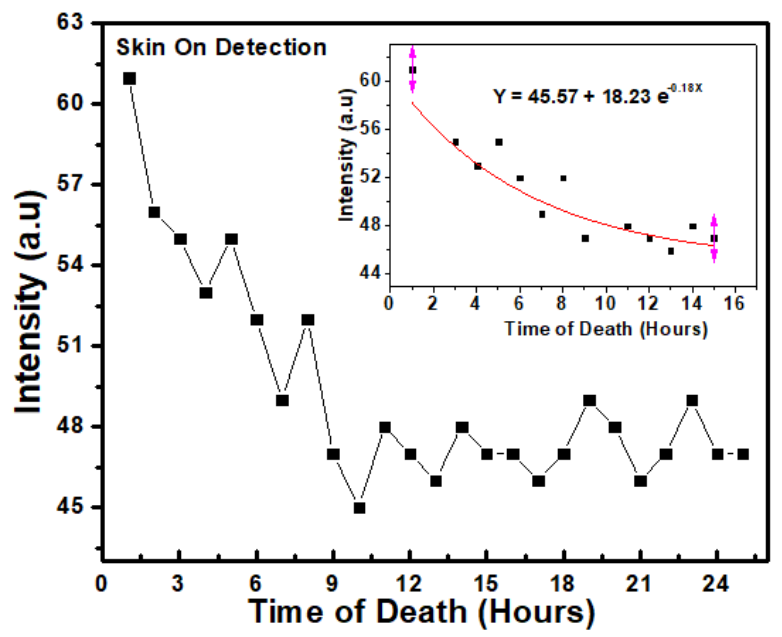

Fig. 6. Skin On detection of Milkfish

Entering the 12-hour period after death, there is a significant decrease in the intensity of reflection as shown in Figure 6 along with fish that have entered the post rigor stage [11]. This stage explained that the fish has issued mucus from the body in accordance with detection of the whole milkfish. The period after 12 hours until the end of the reflection intensity measurement is still decreased accompanied by the smell of foul odor from fish due to more mucus coming out and containing many nitrogen compounds.

In general, the quality of milkfish testing in 1 to 14 hours of death during the Rigormortis phase can be seen clearly. From Figure 6, the freshness of milkfish reflects the exponential decrease when the Rigormortis phase is similar to the condition of whole milkfish (whole fish). From the test results for milkfish under Skin On condition, the fitting 
results obtained inset of the Fig.6with the same method for the data on the milkfish test conditions for whole conditions. The value of Fish Freshness Reduction Constant is 0.188. This value is greater than that of milkfish in whole conditions which is equal to 0.33 . This proves that the condition of Milkfish with Skin On (headless fish and entrails) has a longer freshness level compared to Bandeng fish in whole condition. Milkfish with whole conditions (whole fish) have a faster decrease in freshness due to the bacteria Pseudomonas, Proteus Achromobacter, Terratia, and Elostridium [11]. After the fish die the body temperature of the fish rises, causing these bacteria to attack immediately. Destruction of fish body tissues is imminent, so that over time there will be changes in the composition of the meat. Causing the fish to rot.

\section{Reflection Patterns on Skin Less Milkfish (fillet meat)}

Skin Less fish which are part of the fish during the whole test period have decreased reflection intensity. Because this section has no mucus or mucous layer at the beginning of the measurement has a greater reflectivity. The pattern of decreasing the intensity of infrared reflection in the initial period of up to 2 hours (pre-rigor) after the death of milkfish has decreased the intensity of the reflection though not significantly. This is because at this time the quality of fish is still in good condition.

A period of 12 hours after death occurs a significant change from the decrease in reflection of fish intensity, this is in line with the entry of fish during the post rigor period, which is 10 hours after the initial death [11]. After passing through that period until the end of the measurement the intensity of the infrared reflection still decreases as in Fig. 7. However, the intensity of the changes is not like what happened during the post rigor stage.

From the data obtained by detector, then a graph is made showing the intensity of the decrease in the quality of the milkfish condition using skinless sensors, as follows:

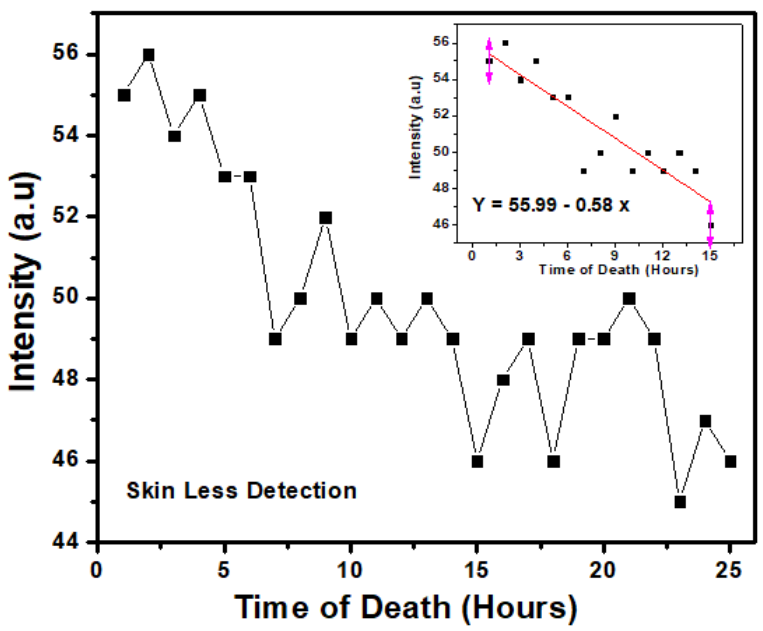

Fig. 7. Skinless detection of Milkfish

In general, the quality of milkfish testing in 1 to 14 hours of death during the Rigormortis phase can be seen clearly. From Fig.7, the data of the milkfish freshness level reflects the linear decrease during the Rigormortis phase. The decrease of freshness of fish in the condition of Skin Less (fillet meat) is different from the condition of whole fish and
Skin On so that the equation used for fitting is used linear mathematical equation that is, where $\mathrm{Y}$ shows the intensity of reflection of infrared light after hitting the fish, $\mathrm{X}$ is the time that starts when mortality from fish, while B is the gradient related to how big the level of freshness decreases in fish. The results of data fitting can be shown in Fig. 7. From the equation, we got the gradient / slope for Milkfish under Skin Less condition 0.58. These results indicate that the level of freshness of Milkfish in Skin Less is longer than in Milkfish in Whole and Skin On conditions. This is due to the fish body which often becomes targeted by bacterial attack is the entire surface of the body, stomach contents and gills. Fillets do not include bacterial attack targets.

\section{CONCLUSION}

Measurement of fish freshness is an important aspect in the field of fisheries, because fish are a high-perishable commodity so handling them requires time that must be fast. The measuring instrument for the freshness of fish that was developed has been able to show changes in the value of reflectance back in line with the decline in the quality of fish freshness. This detector is able to provide better measurement results for milk fish. From the test results also produced that the milkfish in the form of fillets has a high degree of durability of freshness compared to other forms.

\section{REFERENCES}

[1] Z. Usydus and J. Szlinder-Richert, "Functional Properties of Fish and Fish Products: A Review," International Journal of Food Properties, vol. 15, no. 4, pp. 823-846, Jul. 2012.

[2] G. Olafsdóttir et al., "Methods to evaluate fish freshness in research and industry," Trends in Food Science \& Technology, vol. 8, no. 8, pp. 258-265, Aug. 1997.

[3] J. Gu, N. He, and X. Wu, "A New Detection Method for Fish Freshness," in 2014 Seventh International Symposium on Computational Intelligence and Design, Hangzhou, China, 2014, pp. 555-558.

[4] J. Zhou, X. Wu, Z. Chen, J. You, and S. Xiong, "Evaluation of freshness in freshwater fish based on near infrared reflectance spectroscopy and chemometrics," LWT, vol. 106, pp. 145-150, Jun. 2019.

[5] S. Guney and A. Atasoy, "Fish freshness assessment by using electronic nose," in 2013 36th International Conference on Telecommunications and Signal Processing (TSP), Rome, Italy, 2013, pp. 742-746.

[6] A. Atasoy, U. Ozsandikcioglu, and S. Guney, "Fish freshness testing with Artificial Neural Networks," in 2015 9th International Conference on Electrical and Electronics Engineering (ELECO), Bursa, Turkey, 2015, pp. 700-704.

[7] M. K. Dutta, A. Issac, N. Minhas, and B. Sarkar, "Image processing-based method to assess fish quality and freshness," Journal of Food Engineering, vol. 177, pp. 50-58, May 2016.

[8] J. Zhang, Y. Li Xiao, W. Wang, S. Jiao, Y. Zhang, and M. Si Kui, "Non-invasive Assessment of Fish 
Freshness with Bio-impedance and BP-ANN Method," in 2009 Fifth International Conference on Natural Computation, Tianjin, 2009, pp. 232-235.

[9] L. Wu, H. Pu, and D.-W. Sun, "Novel techniques for evaluating freshness quality attributes of fish: A review of recent developments," Trends in Food Science \& Technology, vol. 83, pp. 259-273, Jan. 2019.

[10] N. Shine, F. A. Wibisono, E. Anggadjaja, and T. Rochadiani, "Food Products Monitoring Machine Using Combinations of Multiple Autonomous Sensors," in 2018 10th International Conference on Information Technology and Electrical Engineering (ICITEE), Kuta, 2018, pp. 152-157.

[11] M. L. Perceka, T. Nurhayati, and S. Nuryati, "HISTOLOGICAL CHANGES ON MILKFISH SKIN (Chanos chanos) DURING POSTMORTEM," KLS, vol. 2, no. 1, p. 162, Feb. 2015. 